https://doi.org/10.7203/Normas.1.4648

\title{
INNOVACIONES ACADÉMICAS ACTUALES EN LA ORTOGRAFÍA DE LOS EXTRANJERISMOS EN LA LENGUA ESPAÑOLA
}

\author{
ACADEMIC INNOVATIONS IN THE ORTHOGRAPHY OF FOREIGN WORDS IN THE \\ SPANISH LANGUAGE
}

\author{
David GIMÉNEZ FOLQUÉS \\ Universitat de València
}

\section{RESUMEN:}

En la actualidad, los extranjerismos representan un fenómeno muy importante en la evolución de la lengua española. Por ello, ante las últimas oleadas de voces extranjeras, las actuales obras académicas las recogen y ordenan con el fin de mantener la integridad de la lengua. Obras como el Diccionario panhispánico de dudas, la Ortografía de la lengua española y Las normas académicas: últimos cambios revisan todo este caudal léxico con el objetivo de mantener el ideal de unidad lingüística entre las diferentes zonas hispanohablantes. En el horizonte se vislumbra el tono panhispánico que tanto se ha cuidado desde la Real Academia Española y la Asociación de Academias de la Lengua Española. Ante esta situación, es importante que la lengua no se fragmente con la incorporación excesiva de estos extranjerismos, ya que la situación de unidad es la que asegura un futuro panhispánico uniforme en nuestra lengua. Los cambios ortográficos ante la adaptación de las voces extranjeras representan uno de los principales campos de batalla en la revisión de las mismas. Desde las obras académicas se ha intentado que la ortografía de estas voces extranjeras se adapte a formas propias de la lengua española. Así pues, en este artículo nos hacemos eco de los últimos cambios ortográficos que se han realizado y observaremos en qué estado se encuentra nuestra lengua después de estas revisiones y sus respectivas propuestas.

PALABRAS CLAVE: extranjerismos, innovaciones ortográficas, Real Academia Española, Asociación de Academias de la Lengua Española, Ortografía (2011), Diccionario panhispánico de dudas, lengua española, normas académicas, panhispánico.

\section{ABSTRACT:}

Nowdays, the foreign words are an expanding group in the Spanish language. In fact, the Diccionario panhispánico de dudas, the Ortografía de la lengua española and Las normas académicas: últimos cambios have studied and classified this group of words. The aim of the Royal Spanish Academy and the Association of Spanish Language Academies has been to defend the unity of the Spanish language in the Spanish-speaking areas. Therefore, most of these foreign words are adapted to the Spanish orthography and pronunciation. Sometimes, these adaptations are different between Spain and America, but the Royal Spanish Academy and the Association of Spanish Language Academies show all the possibilities. Therefore, in this 
article we study the orthographic innovations and the linguistic situation of these foreign words in the Spanish language.

KEY WORDS: foreign words, orthographic innovations, Ortografía (2011), Diccionario panhispánico de dudas, Royal Spanish Academy, Association of Spanish Language Academies, Spanish language.

\section{INTRODUCCIÓN}

El 17 de diciembre de 2010, bajo el amparo de la Real Academia Española y de la Asociación de Academias de la Lengua Española, se presenta la nueva edición de la Ortografía de la lengua española, que viene a sustituir a la anteriormente vigente, de 1999. Aparece bajo la perspectiva de la política lingüística panhispánica, como viene siendo habitual en las publicaciones académicas actuales. Su objetivo es el de describir el sistema ortográfico de la lengua española y realizar una exposición pormenorizada de las normas que rigen su correcta escritura en la actualidad.

Dentro de esta perspectiva ortográfica, tiene cabida el uso de los extranjerismos que aparecen tanto en España como en Hispanoamérica. Se habla de ambas zonas hispanohablantes por el ideal de unidad lingüística que se ha perseguido con la aparición de las últimas obras académicas, tales como la Nueva gramática de la lengua española, el Diccionario panhispánico de dudas o la misma Ortografía de la lengua española.

Así pues, la RAE y la Asociación de Academias de la Lengua Española se han marcado una serie de objetivos que ven su reflejo en esta Ortografía revisada. Estos objetivos se resumen en la ya comentada necesidad de mantener la unidad de la lengua; el principio de economía lingüística y la resistencia a cambios drásticos que supongan una ruptura entre la forma gráfica de las palabras y su pronunciación, esta última postura la podemos observar mejor en las páginas de la Real Academia Española (2010c: 22):

[...] el peso de la tradición ortográfica heredada [...] establece un fuerte vínculo entre las palabras y su forma gráfica fijada. Así, cualquier cambio drástico en la grafía de una palabra se siente más como una deformación que desfigura su identidad visual que como una simplificación beneficiosa, lo que explica la fuerza que el criterio del uso constante ha tenido y tiene en la fijación de la ortografía de las lenguas. Una ruptura radical con la tradición gráfica anterior dificultaría, además, la lectura de textos de otras épocas, a los que habría que sumar los costes económicos que supondría la adaptación a las nuevas normas de todas aquellas obras escritas conforme al sistema ortográfico precedente, y el sinfín de cambios que habría que realizar en todos aquellos ámbitos relacionados de algún modo con el lenguaje natural (diccionarios, bases de datos, aplicaciones informáticas, etc.

Como podemos observar, la Ortografía se basa en el peso de la historia para fortalecer su ideal de identidad. Además, añaden el criterio de economía lingüística, ya 
que el hecho de mantener la tradición lingüística permitirá no tener que realizar cambios en la mayoría de obras ya escritas.

Un punto importante en esta cuestión es el uso de extranjerismos; ya que muchos de ellos contienen grafías ajenas a la de la lengua española. Por ello, la RAE considera que ante la masiva llegada de préstamos a nuestra lengua durante las últimas décadas era necesaria una revisión bastante amplia ${ }^{1}$, donde hubiera un control lingüístico de los mismos. De esta manera, se intenta que estas nuevas voces lleguen a adaptarse al sistema de la lengua española tanto en forma como en pronunciación ${ }^{2}$. De no producirse este control, la Real Academia Española (2010c: 598) señala que se produciría un proceso de desestabilización:

Aunque, como se ha visto, el fenómeno del préstamo lingüístico es algo natural que no cabe censurar en modo alguno, es necesario tener en cuenta que la proliferación indiscriminada de extranjerismos crudos o semiadaptados en textos españoles puede resultar un factor desestabilizador de nuestro sistema ortográfico, especialmente cuando se ponen en circulación grafías que se apartan del sistema de correspondencias entre grafemas y fonemas propio de nuestra lengua. De ahí que la Real Academia Española, junto con el resto de las que con ella integran la Asociación de Academias de la Lengua Española, siendo las instituciones encargadas de preservar la coherencia y la unidad del español, procuren orientar los procesos de adopción de extranjerismos para que su incorporación responda, en lo posible, a nuevas necesidades expresivas y se produzca dentro de los moldes propios de nuestra lengua.

Así pues, la Ortografía trata de adaptar las formas extranjeras al sistema ortográfico español. Por ello, en el presente trabajo incluimos las referencias que hace la obra hacia estas formas extranjeras, donde aparecen muchas novedades; algunas de estas ya las encontramos en otras obras académicas como el Diccionario panhispánico de dudas. Las más novedosas también las recoge Gómez Torrego (2011), novedades que citamos en cada uno de los apartados que adjuntamos a continuación.

Finalmente, distribuiremos los apartados en grafías para una mayor clarificación de la información, e incluiremos la situación ortográfica actual de cada una de ellas, en cuanto a usos extranjeros se refiere. Es decir, los criterios que la RAE considera más apropiados para la adaptación de estas grafías y las excepciones que puedan surgir. Todo ello, con la mayor cantidad de ejemplos posible ${ }^{3}$.

\footnotetext{
${ }^{1}$ Revisión ya realizada por el Diccionario panhispánico de dudas de una manera pormenorizada y ampliada en la Ortografía de la lengua española.

${ }^{2}$ Ejemplos de este proceso de adaptación serían los siguientes: balé por ballet, sérif por sheriff $\mathrm{y}$ gueisa por geisha.

${ }^{3}$ Extraídos de la Real Academia Española (2010c) y de Gómez Torrego (2011).
}

NORMAS. REVISTA DE ESTUDIOS LINGÜÍSTICOS HISPÁNICOS, NÚMERO 1 (AÑO 2011): http://www.uv.es/normas 


\section{LA ORTOGRAFÍA DE LOS EXTRANJERISMOS}

\section{1. Las grafías b y $\mathrm{v}$}

En general, el uso de las grafías $b$ y $v$ depende casi siempre de criterios etimológicos, es decir, de la configuración gráfica de su étimo. De este modo, la mayoría de palabras extranjeras mantienen la $b$ o $v$ etimológicas: boceto (del italiano bozzetto), convoy (del francés convoi), overol ${ }^{4}$ (del inglés overall), taburete (del francés tabouret), tobogán (del inglés toboggan), valija (del italiano valigia).

Aunque también podemos encontrar factores antietimológicos en la adaptación de algunos extranjerismos a la lengua española: $\operatorname{arquitrabe}^{5}$ (del italiano architrave), arribista (del francés arriviste), esbelto (del italiano svelto) o rendibú ${ }^{6}$ (del francés rendez vous).

La Real Academia Española (2010c: 93) señala que la aparición de estas excepciones tienen una explicación difícil:

Las razones que explican la existencia de estas grafías antietimológicas impuestas por el uso son distintas en cada caso y responden a factores muy diversos, difíciles de sistematizar, como pueden ser, entre otros, la analogía con palabras semánticamente relacionadas (caso, por ejemplo, de arribista 'persona que progresa por medios rápidos y sin escrúpulos', cuya $b$ antietimológica se explica por analogía con arribar y arriba).

Con la presencia de estas excepciones, muchas veces resulta difícil determinar el uso de $b$ y $v$. Sin embargo, la Ortografía señala algunas pautas orientativas. Entre ellas, hay algunas que afectan a los extranjerismos como:

a) Se emplea $b$ en posición final de palabra: $c l u b$, esnob etc. Son excepción los extranjerismos de procedencia eslava molotov y $l e v^{7}$, así como las transcripciones al alfabeto latino de ciertos nombres propios eslavos, ya sean topónimos, como Kiev, o antropónimos, como los apellidos que contienen las terminaciones patronímicas -ev, -ov: Prokófiev, Romanov.

b) Se emplea $b$ después de las sílabas iniciales $r a-$, ri-, ro-, ru.: rabel $^{8}$, ribete ${ }^{9}$, robinsón ${ }^{10}$ etc. Son excepciones: raviol, ravioli o raviole y

\footnotetext{
${ }^{4}$ Con el significado de 'mono como prenda de vestir'.

${ }^{5}$ Con el significado de 'parte inferior del entablamento, la cual descansa inmediatamente sobre el capitel de la columna'.

${ }^{6}$ Con el significado de 'acatamiento, agasajo que se hace a alguien, por lo general con la intención de adularlo'.

${ }^{7}$ Con el significado de 'moneda de Bulgaria'; variante de la forma preferida leva.

${ }^{8}$ Con el significado de 'instrumento musical pastoril, pequeño, de hechura como la del laúd y compuesto de tres cuerdas solas, que se tocan con arco y tienen un sonido muy agudo'.

${ }^{9}$ Con el significado de 'cinta o cosa análoga con que se guarnece y refuerza la orilla del vestido, calzado, etc'.

${ }^{10}$ Con el significado de 'hombre que en la soledad y sin ayuda ajena llega a bastarse a sí mismo'.
} 
algunos topónimos y sus gentilicios, como Ravena o Rávena (ciudad de Italia) y ravenés.

$c$ ) Se emplea $b$ en las palabras que empiezan por alb-: albornoz, álbum etc.

d) Se emplea $b$ en las palabras que empiezan por bar-: barbacoa, barman etc.

e) Se emplea $b$ en las palabras que empiezan por $b u-$, bur-, y $b u s^{-}$: budín ${ }^{11}$, bufé o bufete, buganvilia, buldócer, bulevar, bumerán, burbon etc.

f) Se emplea $v$ en las palabras que contienen la forma vídeo o video: video o vídeo, videoclip, videoclub etc.

\section{2. Las grafías g y j en representación del fonema $/ y /$}

En algunos préstamos encontramos las letras $j$ y $g$ (ante $e, i$ ) en representación del fonema /y/. Sería el caso de manager o el de junior. Este fenómeno es ajeno al sistema gráfico español. Por lo tanto, cuando se quiera adaptar una voz extranjera a la lengua española se debe hacer sustituyendo estas grafías por la letra $y$, según aconseja la Ortografía de la lengua española: yúnior como adaptación de junior y mánayer como adaptación de manager. Otros ejemplos serían los siguientes: bluyín por blue jean, yacusi por jacuzzi, yincana por gymkhana, yonqui por junkie y yudo por judo.

Si por el contrario, se emplea la grafía y pronunciación originarias, estas formas deben ser consideradas como extranjerismos crudos o no adaptados y escribirse, por lo tanto, en cursiva. La Ortografía incluye ejemplos de ello:

gigolo [yigoló] ('hombre joven mantenido por una mujer mayor a cambio de favores sexuales');

gin [yín] ('ginebra');

ginseng [yínsen] o [yinsén] ('sustancia tónica y estimulante, extraída de una planta del mismo nombre originaria de Corea');

manager [mánayer] ('gerente o directivo de una empresa o sociedad, o representante de un artista o un deportista');

pidgin [pídyin] ('lengua formada por la mezcla de elementos de otras varias, usada entre hablantes de diferente origen lingüístico');

jazz [yás] ('cierto tipo de avión')

\footnotetext{
${ }^{11}$ Variante de pudin o pudín.
}

NORMAS. REVISTA DE ESTUDIOS LINGÜÍSTICOS HISPÁNICOS, NÚMERO 1 (AÑO 2011):

http://www.uv.es/normas 
Una tercera opción, sería la de mantener las grafías originales pero pronunciándolas según nuestro sistema gráfico-fonológico: júnior [júnior] y mánager [mánajer] como explica mejor la Real Academia Española (2010c: 107):

Cuando en un mismo término existen grafías con $-j-$ y con $-y$-, cada una debe pronunciarse según el fonema que representa en español el grafema que contiene, como en soja [sója] y soya [sóya]. Lo que no resultaría posible sería considerar préstamos adaptados como formas en las que existe discordancia entre grafía y pronunciación de acuerdo con nuestro sistema ortográfico; así, la forma judo solo puede considerarse como extranjerismo adaptado si se pronuncia [júdo]; si se pronuncia [yúdo] ha de escribirse en cursiva, como corresponde a los extranjerismos crudos, aunque el hablante tiene también la opción de emplear, en este caso, la grafía adaptada yudo.

La Real Academia Española (2010c: 107) señala casos donde se dan los dos fenómenos:

Hay casos en que un mismo extranjerismo se ha adaptado al español siguiendo ambas pautas: tanto manteniendo la pronunciación originaria y modificando la grafía como manteniendo la grafía originaria y modificando la pronunciación. Así, procedente del inglés jersey existen en español las adaptaciones jersey [jerséi], usada sobre todo en España, y yérsey [yérsei] o yersi [yersi], usadas en América; del mismo modo, del inglés pyjamas proceden las adaptaciones pijama [pijáma], en España, y piyama [piyáma], en América.

\section{3. La grafía $\mathrm{k}$}

Tradicionalmente, la grafía $k$ en los préstamos se solía sustituir por grafías patrimoniales como $c$ o qu en favor de la total adaptación de estos al sistema gráfico español. Ejemplos de esta adaptación serían: canguro, del francés kangourou, cinc o zinc, del alemán Zink, o esmoquin, del inglés smoking.

Sin embargo, en los préstamos de nueva o más reciente incorporación, es más normal que la letra $k$ se mantenga por estar ya integrada en el abecedario del español. Serían los casos de: kamikaze, kayak, kilo, kiwi etc.

Es posible también encontrar la forma etimológica y la adaptada. Así pues, encontraríamos: bikini / biquini, moka / moca, póker / póquer etc.

De esta manera, aunque en muchos casos, especialmente en los préstamos más actuales, se tiende a mantener la grafía etimológica, no se pueden censurar las grafías que se adapten a las pautas gráficas tradicionales en español ${ }^{12}$.

\footnotetext{
${ }^{12}$ Para más información consultar la Real Academia Española (2010c: 116).
} 
Por ello, la existencia de diversas posibilidades gráficas para representar el fonema $/ \mathrm{k} /$ ha dado lugar a numerosos casos de variantes gráficas en la escritura de los préstamos. Algunos casos destacados por la Ortografía donde se observa algunas variantes serían ${ }^{13}$ :

bikini ('traje de baño femenino de dos piezas'), mejor que biquini;

caqui ('color que varía entre el amarillo ocre y el verde grisáceo' y 'árbol oriental y su fruto comestible'), mejor que kaki;

euskera ('lengua vasca'), mejor que eusquera;

folclor(e) ('conjunto de costumbres, tradiciones y manifestaciones artísticas de un pueblo'), folclórico - ca ('del folclore'), folclorista ('estudioso del folclore'), mejor que folklor(e), folklórico -ca, folklorista;

harakiri ('suicidio ritual japonés que consiste en abrirse el vientre'), mejor que haraquiri;

Irak ('país árabe'), mejor que Iraq;

kamikaze ('piloto suicida japonés' y 'persona temeraria o que comete un atentado que puede implicar su propia muerte'), mejor que camicace;

kimono ('túnica japonesa'), mejor que quimono;

koiné ('lengua estándar común, resultado de la unificación de distintas variantes dialectales'), mejor que coiné;

moka ('cierta variedad de café'), mejor que moca;

musaka ('plato típico de la cocina griega'), mejor que musaca;

neoyorquino -na ('de Nueva York'), mejor que neoyorkino -na;

pakistaní ('de Pakistán'), mejor que paquistaní;

pekinés ('de Pekín'), mejor que pequinés -sa;

póker ('cierto juego de naipes'), mejor que póquer;

polca ('danza folclórica de Bohemia'), mejor que polka;

queroseno o en América, querosén, querosene, querosín ('combustible derivado del petróleo'), mejor que keroseno, kerosén, kerosene, kerosín;

quiosco ('templete para celebrar conciertos al aire libre' y 'puesto de venta en la calle'), quiosquero -ra ('persona que atiende un quiosco'), mejor que kiosco, kiosquero -ra;

${ }^{13}$ Muchos de estos préstamos difieren de las adaptaciones propuestas por la Real Academia Española (2005).

NORMAS. REVISTA DE ESTUDIOS LINGÜÍSTICOS HISPÁNICOS, NÚMERO 1 (AÑO 2011):

http://www.uv.es/normas 
telequinesia o telequinesis ('desplazamiento de objetos por la fuerza de la mente'), mejor que telekinesia o telekinesis;

vodka ('cierto aguardiente'), mejor que vodca.

Gómez Torrego (2011: 27) indica que puede haber variantes entre una forma y sus derivados en lo que se refiere a la grafía $k$. Sería la situación de rock. Considera a esta forma como extranjerismo no adaptado por su grafía $c k$, alejada del sistema español. Por ello, debe escribirse con resalte tipográfico, es decir, en cursiva. Sin embargo, su variante será roquero, - $a$ y no *rockero, $-a$.

Por el contrario, el mismos autor señala que los derivados foráneos de nombres propios de persona deben mantener la consonante de estos nombres: steimbeckiano de Steimbeck; kafkiano de Kafka; trotskista de Trotski, kantiano de Kant, etc. Manteniendo, de esta forma, la $k$ original.

\section{4. La secuencia gráfica 11}

Los extranjerismos con la grafía $l l$ que representan un sonido idéntico a nuestro fonema /1/, si se adaptan al español tomando como referencia la pronunciación, deben transformar la $l l$ etimológica en $l$ : a capela por a cappella, balotaje por ballotage, béisbol o beisbol por baseball, dril por drill, pulóver por pullover, salmonela por Salmonella etc.

Además, el dígrafo $l l$ no aparece nunca en español en posición final de sílaba. Así pues, los extranjerismos que se adapten al español deben sustituir la $l l$ final de palabra o de sílaba por una l: buldócer por bulldozer, kril por krill, overol por overall etc.

\section{5. Las grafías $\mathrm{m} y \mathrm{n}$}

En español, el sistema gráfico señala que ante $p$ o $b$ se debe escribir $m$ y no $n$. De este modo, esta misma norma debe aplicarse a los extranjerismos cuando son adaptados al español. Esta norma se debe seguir aunque en su forma original aparezca una $n$. Así se señala en la Real Academia Española (2010c: 90), donde se nos da ejemplos de ello:

[...] debe aplicarse a los extranjerismos, incluidos los topónimos foráneos y sus gentilicios, si se adaptan al español: lumpemproletariado (del alemán Lumpenproletaria), Brandemburgo (en alemán Brandenburg), brandemburgués, Camberra (del inglés Canberra), camberrano.

Sin embargo, desde la Ortografía se nos indica también que la secuencia $n b$ se mantiene en los apellidos extranjeros y sus derivados, ya que en este caso se suele 
mantener la grafía original: Gutenbert, Hartzenbusch, Schönberg, schönbergiano, Steinbeck, steinbeckiano.

Se puede escribir $n$ ante el fonema /b/ cuando se representa con la letra $v$. Este sería el caso de convoy (del francés convoi con el significado principal de 'acompañamiento o séquito' y 'tren como medio de transporte') o el de tranvía, procedente de la palabra inglesa tramway.

Por otro lado, la nasal que se articula ante el fonema $/ \mathrm{f} / \mathrm{es} / \mathrm{n} / \mathrm{y}$ no $/ \mathrm{m} /$. Con lo cual, todos los extranjerismos que originalmente contengan $-m p h-\mathrm{o}-m f$ - deben adaptarse al español con $n$ y no con $m$ : anfetamina por amphetamine, anfibol ${ }^{14}$ por amphibole, panfleto por pamphlet, etc. De esta manera, formas como comfort no serían correctas en español, debería aparecer como confort.

\section{6. La grafía $\mathrm{q}$}

Hablamos ahora de la letra $q$ (sin formar dígrafo con la vocal $u$ ), para la representación del fonema $/ \mathrm{k} /$. En un intento de regularizar la escritura española, en 1815 , se determinó que anglicismos como quark y quásar, que poseían la letra $q$, se escribieran con «cu + vocal». Así, se aconseja escribir estos préstamos de la siguiente forma: cuark, cuásar. Así pues, estas formas ya están plenamente difundidas en la lengua española ${ }^{15}$.

La Real Academia Española (2010c: 616) incluye los siguientes ejemplos:

Según algunos expertos, la poderosa luz del cuásar sería el alarido de muerte de estrellas devoradas por un agujero negro.

Los investigadores han presentado pruebas decisivas de este nuevo estado de la materia en el que los cuarks, que son probablemente los componentes más pequeños de la materia $[\ldots]$, se desplazan en forma libre.

El hecho de añadir una grafía más, la $q$, a las tres que ya existen para representar el fonema $/ \mathrm{k}$ / (el dígrafo $q u$ y las letras $c$ y $k^{16}$ ), provocaba dispersión en la utilización de los mismos. Por ello, como dictaba la norma establecida en 1815, citada más arriba, para mantener la coherencia y simplicidad del sistema ortográfico español, la Real Academia Española (2010c: 115) recomienda que:

\footnotetext{
${ }^{14}$ Con el significado de 'mineral compuesto de sílice, magnesia, cal y óxido ferroso, de color por lo común verde o negro, y brillo anacarado'.

${ }^{15}$ En especial cuásar. Incluso hoy más frecuente que la forma etimológica.

${ }^{16}$ Para representar el fonema $/ \mathrm{k} /$ existe también los dígrafos $c k$ y $c q$. Estos no pertenecen a ningún sistema gráfico del español. Así pues, si los extranjerismos que los incluyen se adaptan al español lo deben hacer sustituyendo estos dígrafos por las grafías propias de nuestro sistema. Por ejemplo: bloc por block; coctel o cóctel por cocktail; críquet por cricket etc.
}

NORMAS. REVISTA DE ESTUDIOS LINGÜÍSTICOS HISPÁNICOS, NÚMERO 1 (AÑO 2011): http://www.uv.es/normas 
Todos aquellos préstamos de otras lenguas (sean latinismos o extranjerismos) cuya grafía etimológica incluya una $q$ con valor fónico independiente se adapten por completo al español sustituyendo dicha $q$ por las grafías hoy asentadas en nuestra lengua para representar el fonema $/ \mathrm{k} /$ [...]. En caso de mantener la $q$ etimológica, estas voces deben considerarse extranjerismos o latinismos no adaptados y escribirse, por ello, en cursiva y sin tildes: quadrivium, quark, quasar, quorum, exequatur.

\section{7. La secuenciación «s inicial + consonante»}

En español no resulta natural empezar una palabra con $s+$ consonante. Por ello, cuando una voz extranjera con esta secuencia se adapta a nuestra lengua, lo hace añadiendo una $e$ inicial que sirve como apoyo en la pronunciación: escáner por scanner, eslalon por slalom, esmoquin por smoking, espagueti por spaguetti, estándar por standard, estor por store, estrés por stress etc $^{17}$.

También contamos con topónimos en español adaptados de otras lenguas que incluyen la $e$ - inicial de apoyo, serían los casos de: Estocolmo (en sueco Stockholm) o Estrasburgo (en francés Strasbourg).

Aun así, la Real Academia Española (2010c: 126) señala que la $s$ líquida inicial se mantiene en la forma de topónimos extranjeros. El problema viene en sus derivados, donde encontramos algunas excepciones ${ }^{18}$ :

La $s$ líquida inicial se mantiene, no obstante, en la grafía de algunos topónimos foráneos, como Skopie (capital del país cuya denominación oficial provisional es Antigua República Yugoslava de Macedonia) o Sri Lanka (nombre actual de la antigua Ceilán), aunque en los derivados, cuando existen, sí se añade la $e$ - de apoyo: esrilanqués (gentilicio de Sri Lanka). En los derivados de antropónimos, en cambio, aunque en algunos casos se han fijado en el uso grafías con $e$ - inicial, como estalinismo, estalinista (de Stalin, dirigente de la antigua URSS) o estajanovismo, estajanovista (de Stajanov, minero soviético), lo normal es que se mantenga sin cambios la grafía del nombre propio: spengleriano (de Spengler, filósofo alemán) stendhaliano (de Stendhal, escritor francés).

Finalmente, esta $e$ - de apoyo que encontramos en la secuencia con $s$, también la usamos en español en otras secuencias consonánticas iniciales extranjeras como: embayá por mbayá ${ }^{19}$.

${ }^{17}$ Según señala la Ortografia, se trata de un fenómeno bastante común en español, desde sus orígenes, como se puede observar en las numerosas voces patrimoniales que proceden de palabras latinas con $s$ líquida: escala por scala, escena por scena, espejo por specŭlum etc.

${ }^{18}$ También encontramos la $s$ líquida en las locuciones latinas que se usan en español con su grafía originaria, como statu quo o stricto sensu.

${ }^{19}$ Del guaraní. 


\section{8. El dígrafo sh}

El dígrafo $s h$ que representa el fonema /sh/ no pertenece al sistema gráfico español actual. Así pues, las voces que los poseen deben considerarse como extranjerismos crudos y deben escribirse en cursiva. Ejemplos de ello son: flash, show, sushi, etc.

Cuando estas voces se han adaptado al español, lo hacen sustituyendo el dígrafo por alguna forma de nuestro sistema gráfico, normalmente ch o s: chute por shoot, hachís por hashish, champú por shampoo etc.

Un ejemplo significativo es el anglicismo short(s) que según la Real Academia Española (2010c: 127) en América «comienza a escribirse en la forma adaptada chor (pl. chores) e incluso en la forma diminutiva chorcito(s); o con el anglicismo flash, que en España puede verse escrito en la forma adaptada flas»

Excepcionalmente, aparece la sh etimológica en algunos topónimos que mantienen la grafía propia de su lengua original, como por ejemplo Washington (capital de los Estados Unidos) o Shanghái (ciudad de China). Este uso se extiende al de los gentilicios, como sería el caso de washingtoniano.

El caso de estos ejemplos no significa que la Real Academia Española (2010c: 128) recomiende adaptar en lo posible este dígrafo a una forma española:

La existencia de estas grafías no obsta para que se recomiende escribir con simple $s$ muchos topónimos que contienen sh en su grafía originaria, o en la de otras lenguas como el inglés o el francés, pero que en español se pronuncian normalmente con /s/, como es el caso, entre otros, de Bangladés o Ingusetia, grafías más recomendables que Bangladesh e Ingushetia.

Por otra parte, en los nombres de persona y en su derivado sí se mantiene la sh en formas extranjeras: shakespeariano (de Shakespeare, dramaturgo inglés), sherlockiano (de Sherlock Holmes, famoso detective de ficción).

Finalmente, Gómez Torrego (2011: 32) se hace eco de este fenómeno y, además, señala que el fenómeno de la adaptación del grupo $s h$ en $c h$ o $s$, podría crear un precedente en las voces siguientes:

chou (de show), aunque es preferible la palabra espectáculo;

chouman (de showman), si no triunfaran las propuestas del Diccionario panhispánico de dudas: hombre espectáculo, presentador o animador. 


\section{9. La grafía $\mathrm{w}$}

Según la Ortografía, la letra $w$, que no existía en latín, entró en español por la vía del préstamo ${ }^{20}$. Se emplea en voces procedentes de otras lenguas, en las que representa dos fonemas distintos, el vocálico /u/ y el consonántico /b/. Como la $w$ se consideró una letra extranjera durante mucho tiempo en nuestro sistema ortográfico, cuando se pretendía adaptar una voz extranjera con esta grafía a nuestro sistema gráfico se realizaba con otras grafías, tales como $g u, u$ o $v$ : la obra señala como ejemplos los casos de güelfo ${ }^{21}$, del alemán Welf; vagón, del inglés wagon; o suéter, del inglés sweater.

Por otro lado, en la actualidad, al ser considerada como letra perteneciente al abecedario español, se entiende que se conserve en los préstamos la grafía $w$. Por ello, encontramos los casos de: waterpolo, sándwich, web, etc.

Algunas veces, en el fonema vocálico /u/, se dan por válidas ambas grafías, sería el caso de taekwondo o taekuondo, lawrencio o laurencio ${ }^{22}$ etc.

Así pues, hasta que la letra $w$ fue considerada como parte del sistema gráfico español, se adaptaban los préstamos sustituyendo la $w$ por letras españolas como $v, u$ o $g u$. En la actualidad, desde la Ortografía se aboga por el uso de la $w$ etimológica, ya que todos los hablantes hispanos la consideramos hoy en día como propia. Aun así, en el transcurso de estos dos períodos hay préstamos que identificamos como propios por haberse adaptado ya plenamente a nuestra lengua, estos serían los casos de váter, vagón, suéter o vatio.

Como ejemplo de este fenómeno, se explicaría que durante algún tiempo el diccionario académico mostrase únicamente la forma darvinismo como adaptación del inglés Darwinism. Aun así, hoy en día se admite solo la forma darwinismo con la grafía etimológica.

Gómez Torrego (2011: 30) recoge también este fenómeno y habla, en particular, de dos casos: el de kiwi y el de wiski. En el primer caso, el autor señala que se desecha la forma kivi en favor de kiwi, aunque añade que se prefiere la pronunciación con $u$ semiconsonántica [kíui].

\footnotetext{
${ }^{20}$ La letra $w$ se incorporó oficialmente al abecedario español en 1969. En origen fue un dígrafo por duplicación de la $v$ latina. En español, durante la Edad Media, se empleó inicialmente para determinados nombres propios de origen germánico.

${ }^{21}$ La Real Academia Española (2001) indica que su uso viene de la Edad Media y lo define como: 'partidario de los papas contra los gibelinos, defensores de los emperadores de Alemania'.

${ }^{22}$ Según la Real Academia Española (2001) 'elemento químico transuránico de núm. atóm. 103. Se obtiene artificialmente por bombardeo de californio con iones de boro, pertenece a la serie de los actínidos, y su vida media es de ocho segundos'.
} 
En el segundo caso, Gómez Torrego señala que se propone por primera vez la forma wiski como adaptación de whisky o whiskey, en lugar de la anterior adaptación güisqui ${ }^{23}$. La justificación la encuentra por su aparición en documentos literarios.

\section{10. La grafía $\mathrm{z}$ ante $\mathrm{e}, \mathrm{i}$}

En español, algunas palabras extranjeras introducen términos que empiezan con $z$ ante $e$ y $i^{24}$. Estas formas se mantienen porque estaban en su grafía originaria o en su transcripción a nuestro alfabeto. Ejemplos de este fenómeno sería: kamikaze, nazi, zéjel, zen, zepelín, zigurat ${ }^{25}$, zigzag, zíper etc.

Entre estas formas, también encontramos topónimos y antropónimos originarios de otras lenguas y sus derivados. La Real Academia Española (2010c: 124) aporta ejemplos sobre este fenómeno:

Azerbaiyán (y sus gentilicios azerbaiyano y azerî), Nueva Zelanda (y su gentilicio neozelandés), Suazilandia (y su gentilicio suazi), Zimbabue (y su gentilicio zimbabuense), Elzevir (apellido de una célebre familia de impresores holandeses, y sus derivados elzevir o elzevirio y elzeviriano), Ezequiel, Zenón, Zeus.

Pese a ello, estas formas son ajenas a la lengua española. En las voces patrimoniales españolas suele aparecer en este contexto la letra $c$. Por lo tanto, según la Real Academia Española (2010c: 618) «no resulta extraño encontrar variantes gráficas en muchos extranjerismos. Junto a la grafía que mantiene la $z$ etimológica, presentan grafías con $c$, plenamente adaptadas a la ortografía del español». Así pues, estas variantes han aparecido por la convivencia en el uso de grafías etimológicas con $z$, junto a grafías adaptadas al sistema gráfico del español que utiliza $c$.

La Ortografía incluye algunos ejemplos de esta alternancia:

acimut/azimut ('ángulo que con el meridiano forma el círculo vertical que pasa por un punto de la esfera celeste o del globo terráqueo');

cigoto/zigoto ('célula resultante de la unión del gameto masculino con el femenino');

cinc/zinc ('cierto metal');

\footnotetext{
${ }^{23}$ Se refiere a la adaptación que propuso la RAE (2001) y el $D P D$.

${ }^{24}$ Especialmente cultismos griegos, arabismos y préstamos de otras lenguas.

${ }^{25}$ En arquitectura: 'Torre escalonada y piramidal, característica de la arquitectura religiosa asiria y caldea'.
}

NORMAS. REVISTA DE ESTUDIOS LINGÜÍSTICOS HISPÁNICOS, NÚMERO 1 (AÑO 2011):

http://www.uv.es/normas 
cíngaro -ra/zíngaro - ra ('gitano');

circón/zircón ('silicato de circonio');

eccemaleczema ('afección cutánea que produce descamación en la piel');

magacín/magazín ('revista ilustrada sobre temas diversos' y 'programa de radio o televisión de contenido muy variado').

\section{11. Las terminaciones con-age/-aje}

En la lengua española, hemos contado con voces francesas terminadas en -age (pronunciación [áz]), que se han adaptado al español con la grafía -aje (pronunciación [áje]).

Actualmente, cuando se adaptan al español este tipo de galicismos también lo hacemos con la terminación -aje: bricolaje por bricolage, garaje por garage, etc.

La Real Academia Española (2010c: 102) incluye más ejemplos de esta adaptación: «aterrizaje por atterrissage, brebaje por breuvage, camuflaje por camouflage, chantaje por chantage, espionaje por espionnage, masaje por massage, potaje por potage, tatuaje por tatouage.

La Ortografía señala que si se utilizan estas voces francesas sin adaptar, con su grafía y pronunciación originarias, deben escribirse en cursiva, para destacar así su situación de extranjerismo crudo.

Así pues, en muchas zonas de América se prefiere la forma cruda a la adaptación española. Por ejemplo, en la voz garage (pronunciado [garáz]), en lugar de la adaptación garaje (pronunciado [garáje]).

\section{12. Las terminaciones con -ing}

Tradicionalmente, las voces inglesas con la terminación -ing se han adaptado a la lengua española cambiando esta terminación por -in. Este hecho se ha dado porque la grafía no se representaba en la pronunciación de los hispanohablantes. Ejemplos de esta adaptación serían: mitin por meeting, pudin o pudín por pudding, esmoquin por smoking etc.

También se encuentra esta adaptación en los anglicismos actuales acabados en la sílaba -ing. Se puede dar por su falta de equivalentes en la propia lengua, o por su 
arraigo y generalización en el uso actual: campin por camping, castin por casting ${ }^{26}$, cáterin por catering, márquetin por marketing ${ }^{27}$, pirsin por piercing etc.

Finalmente, Gómez Torrego (2011: 31) señala que este es el camino que podrían seguir otros anglicismos si se decidiera su adaptación al español. E incluye los siguientes ejemplos:

bulin (de bullying), si no triunfara un posible sustituto como el de acoso escolar (aparece también la forma bulling en los medios);

estrechin (de stretching ${ }^{28}$ );

fisin (de phishing ${ }^{29}$ );

futin (falso anglicismo formado en español con foot e -ing), si no triunfaran las formas aerobismo o el infinitivo trotar propuestas en el Diccionario panhispánico de dudas;

lisin (de leasing ${ }^{30}$ );

mobin (de mobbing), si no triunfara la propuesta del Diccionario panhispánico de dudas acoso laboral;

puentin (forma híbrida formada con el sustantivo español puente y la terminación inglesa -ing), en el caso de que no triunfe el sustituto español puentismo propuesto en el DPD;

rentin (de renting);

surfin (de surfing), como variante de surf;

yoguin (de jogging).

Gómez Torrego, en algunas de estas formas, cuando indica una hipótesis de adaptación, lo hace diciendo que esa hipótesis se dará si no triunfa el equivalente español propuesto por la Real Academia Española, esto lo dice porque la RAE aconseja siempre el uso del equivalente español, por encima de la propia adaptación, para mantener la integridad de la lengua. Por ello, por ejemplo, si la forma española puentismo acaba triunfando, no será necesario utilizar ni la forma cruda puenting, ni su hipotética adaptación puentin. Lo mismo sucedería con las forma mobbing (o su adaptación mobin), innecesarias si triunfa la voz española que aconseja el DPD acoso laboral, o el extranjerismo bullying (con su adaptación bullin) en favor de la forma española acoso escolar. Llamativo es el caso de footing (plenamente adaptada al

\footnotetext{
${ }^{26}$ Aunque se prefiere el equivalente español audición.

${ }^{27}$ Aunque se prefiere el equivalente mercadotecnia.

${ }^{28}$ Con el significado de 'estiramiento'.

${ }^{29}$ Con el significado de 'engaño informático'.

${ }^{30}$ Con el significado de 'contrato de arrendamiento de medios de producción'.
} 
español) donde el $D P D$ aconseja las formas aerobismo o trotar. El tiempo dirá qué formas acaban triunfando ${ }^{31}$.

\section{13. Las voces terminadas en $-\mathrm{y}$ precedidas de consonante}

Las palabras terminadas en $y$ precedida de consonante son propias de los préstamos, ya que en español, solo se admite la terminación en y cuando va precedida de vocal. Las palabras terminadas en $y$ precedidas de consonante suelen pertenecer a la lengua inglesa: curry, dandy, derby, ferry, panty, penalty, pony etc.

Ya que este fenómeno es ajeno al español, cuando se quieren adaptar estos préstamos, lo deben hacer sustituyendo la $y$ final por $i$ : curri por curry, dandi por dandy, derbi por derby, ferri por ferry, panti por panty, penalti por penalty, poni por pony, sexi por sexy etc.

Por otro lado, tampoco es propio del español actual las palabras con $y$ con valor vocálico en posición interior de palabra. De esta forma, también es normal que cuando se adapten estas voces al español, lo hagan con $i$ en lugar de la y: géiser por geyser, pijama o piyama por pyjamas.

Resulta una excepción el término byte, ya que según la Real Academia Española (2010c: 81): «El término byte (pronunciado [báit]) es un extranjerismo crudo o no adaptado, motivo por el cual conserva su grafía y su pronunciación originarias».

Por el mismo motivo, cuando un término acabado en $y$ forma su plural (añadiendo una $s$ ) lo debe hacer, también, cambiando la $y$ por $i$, ya que conserva en el plural su valor vocálico: así el plural de jersey debe ser jerséis; el de espray, espráis; el de gay, gais etc. En cambio, si para añadir el plural se utiliza -es, se conserva la y del singular, ya que en el plural representa el fonema consonántico /y/: bueyes (de buey), convoyes (de convoy), virreyes (de virrey), etc.

La Ortografía sí permite que se mantenga la $y$ final si esta va precedida de una o dos vocales con las que forma un diptongo o un triptongo: bocoy, tepuy, yóquey etc.

En ciertos términos extranjeros se admiten ambas grafías, con $-y$ y con $-i$ : bonsái/bonsay, paipái/paipay, samurái/samuray y tipói ${ }^{32} /$ tipoy.

${ }^{31}$ Normalmente, según Giménez Folqués (2010) suelen influir factores como la moda lingüística, la comodidad en la pronunciación y la influencia de los medios de comunicación.

${ }^{32}$ En América: 'túnica larga de manga muy corta y escote cuadrado'. 


\section{14. Las consonantes dobles}

Las consonantes dobles o geminadas en español son rechazadas si dicha duplicación no tiene reflejo en la pronunciación. Así, los préstamos de otras lenguas que en su grafía originaria contengan dos consonantes iguales seguidas, si son adaptadas al español lo hacen simplificando las dos consonantes a una. La Ortografía incluye varios ejemplos de esta simplificación: driblar de to dribble, brócoli de broccoli, racor de raccord, adenda de addenda, pudin o pudín de pudding, chofer o chófer de chauffeur, esnifar de to sniff, grogui de groggy, zigurat de ziggurat, a capela de a cappella, chambelán de chambellan, consomé de consommé, canelón de cannellone, escáner de scanner, chóped de chopped, dosier de dossier, estrés de stress, confeti de confetti, cúter de cutter, esbozar de sbozzare, o puzle de puzzle.

Por ello, en las nuevas adaptaciones debe aplicarse la misma pauta: cadi de caddie, chédar de cheddar, pádel de paddle, suflé de soufflé, rali de rally, osobuco de ossobuco, mozarela de mozzarella. Así pues, los extranjerismos que no aparecen adaptados, como es el caso de pizza o jazz, se considerarán extranjerismos crudos.

También utilizamos este tipo de adaptación en los topónimos foráneos: Adís Abeba (capital de Etiopía, de Addis Ababa), Búfalo (ciudad de EE.UU., de Buffalo), Lausana (ciudad de Suiza, de Lausanne), Mesina (ciudad de Italia, de Messina), Misisipi (río y estado de EE.UU., de Mississippi) o Róterdam (ciudad de los Países Bajos, de Rotterdam).

Según la Real Academia Española (2010c: 179) existen algunas excepciones donde se mantienen las consonantes dobles:

Excepcionalmente, se mantienen las secuencias de dos grafemas consonánticos iguales en los nombres de algunas letras del alfabeto griego (y en sus derivados), que son transcripción literal del original griego: kappa, digamma y gamma (y sus derivados gammagrafía y gammaglobulina).

También se conserva la doble consonantes etimológica en antropónimos o en topónimos foráneos no adaptados, y en sus derivados. Aunque no necesariamente la grafía tenga reflejo en la pronunciación: heideggeriano (de Heidegger, filósofo alemán), popperiano (de Popper, filósofo austriaco), picassiano (de Picasso, pintor español), Ottawa (capital de Canadá) y su gentilicio ottawense, etc.

Por otro lado, nombres propios de persona pueden presentar alternancia con la doble consonante y su simplificación: Gemma/Gema, Emma/Ema o Emmanuel/Emanuel ${ }^{33}$.

33 También, según la Real Academia Española (2010c: 179) conserva la doble consonante el prefijo del sistema internacional de unidades atto-, proveniente de la palabra noruega y danesa atten

NORMAS. REVISTA DE ESTUDIOS LINGÜÍSTICOS HISPÁNICOS, NÚMERO 1 (AÑO 2011):

http://www.uv.es/normas

(ISSN 2174-7245) 


\section{CONCLUSIONES}

Como hemos podido comprobar, la primera conclusión que podemos extraer del trabajo de la Ortografía en el uso de extranjerismos es la necesidad de acercar estas voces al sistema ortográfico español. Por ello, intenta dejar de lado las grafías que resultan ajenas, como por ejemplo las consonantes dobles (broccoli), la terminación -ing (renting), el dígrafo sh (shampoo), o la secuenciación «s + consonante» (spaguetti); por otras grafías más cercanas al sistema español: brócoli, rentin, champú, espagueti.

Con el paso de las últimas obras académicas, hemos podido ir observando cómo se ha ido radicalizando la postura en torno a los extranjerismos crudos. No prohíben su uso, pero sí se inclinan hacia los equivalentes en español, si los hubiere, o en su defecto a las adaptaciones a formas españolas.

De esta manera, tenemos como resultado dos clases de extranjerismos, los que se adaptan al español y los que se resisten a adaptarse manteniendo su forma original. Esta resistencia suele provenir de varios factores, como el prestigio de la palabra, su extensión en el uso o por la influencia de los medios de comunicación.

Los que sí son adaptados lo hacen por medio de varios procedimientos según señala la Real Academia Española (2010c: 602):

La mayor parte de las veces, la adaptación de los extranjerismos se realiza modificando la grafía originaria para adecuarla, según nuestras reglas ortográficas, a la pronunciación de esas voces en español, que suele aproximarse a la que tienen en la lengua de origen. En la grafía adaptada se prescinde normalmente de los grafemas del original que no tienen reflejo en la dicción española y se aplican las reglas de acentuación gráfica propias de nuestro idioma $[\ldots]$.

A veces la adaptación solo requiere la aplicación de la tilde, como en ambigú (del fr. ambigu), bádminton (del ingl. badminton), blíster (del ing. blister) o máster (del ingl. master). Y, en algunas ocasiones, el extranjerismo no plantea ningún problema de inadecuación entre grafía y pronunciación de acuerdo con la ortografía del español, y se incorpora a nuestra lengua con la misma grafía que tiene en el idioma de origen, como ocurre con box, kit o set, voces tomadas del inglés que se pronuncian en español tal como se escriben: [bóks], [kit] y [sét].

En otros casos, se mantiene la grafía originaria sin cambios o con leves modificaciones, y es la pronunciación de los hispanohablantes la que se acomoda a dicha grafía, aunque al hacerlo se aparte de la pronunciación original de la voz extranjera.

Lo que sí queda claro, es que si se utiliza la grafía extranjera original, esta debe ir marcada en cursiva. Mientras que, cuando el extranjerismo se ha adaptado con la grafía propia española, esta ya puede aparecer en letra redonda.

('dieciocho'), que se aplica a nombres de unidades de medida para formar los nombres de los submúltiplos un trillón de veces inferiores, como en attosegundo. 
Por otro lado, en cuanto a estas adaptaciones se refiere, Gómez Torrego (2011), además de recogerlas junto con las propuestas de la Ortografía de la lengua española, también propone previsiones de futuras adaptaciones según los criterios observados en la Real Academia Española. Sería el caso de la voz show, donde según la Real Academia las palabras que contienen el dígrafo sh se deben adaptar con grafías propias españolas, así pues, el autor propone la voz chou. Lo mismo sucede con las palabras terminadas en -ing y con la palabra renting en favor de rentin (voz propuesta por Gómez Torrego).

Aunque se trate de seguir unas pautas en cuanto a la adaptación de ortografías extranjeras al sistema ortográfico español, muchas veces, es inevitable encontrarse con excepciones que complican esta sistematización. Sería el caso de los topónimos Washington y Shanghái que mantienen el dígrafo $s h$; o cuando se emplea $b$ en posición final de palabra pero nos encontramos con las voces eslavas: molotov o lev que acaban en $v$.

Algunas de estas excepciones vienen por la permisividad que da la Real Academia Española (2010c: 37) a algunas formas etimológicas:

En la configuración del sistema ortográfico del español ha operado también, aunque con menor incidencia que en lenguas como el inglés o el francés, el criterio etimológico, según el cual, en la escritura de las palabras, debe respetarse en alguna medida la forma gráfica de su étimo, es decir, del término del cual derivan. Este criterio funciona, en muchos casos, en sentido opuesto al fonológico, y explica por qué la forma escrita de determinadas palabras contradice el principio básico de adecuación entre grafía y pronunciación [...].

La aplicación del criterio etimológico explica también muchas de las excepciones a las reglas generales (por ejemplo, la presencia de $z$ ante las vocales $e, i$ en la escritura de ciertas palabras por figurar dicha letra en su étimo, como en zeugma o nazi), y es asimismo la causa de la mayor parte de las desviaciones del ideal de correspondencia biunívoca entre grafemas y fonemas que hay en nuestro sistema ortográfico, desde la presencia de un grafema, como la $h$, sin valor fonológico, hasta la existencia de varias posibilidades gráficas para representar un mismo fonema ( $b, v$ y $w$ para $/ \mathrm{b} / ; j$ y $g$ para $/ \mathrm{j} /$, etc.) De hecho, el criterio etimológico sigue operando hoy a la hora de fijar la grafía de aquellas palabras que contienen fonemas que admiten varias representaciones gráficas, pues lo habitual es respetar, en esos casos, los grafemas etimológicos; así, voces como káiser, anorak o búnker se escriben con $k$ (y no con $c$ ni con $q u)$ por ser esa la letra que aparece en su étimo.

Así pues, están claras las posturas de la RAE y Asociación de Academias en torno al uso de los extranjerismos en un futuro. El control y la revisión de los mismos será la constante que encontraremos. Dentro de este control, la españolización de estas voces será el objetivo primordial, ya que de esta forma, se aseguran la integridad y el equilibrio de la lengua en el afán de mantener el ideal de unidad linguiística entre las diferentes zonas hispanohablantes. 


\section{REFERENCIAS BIBLIOGRÁFICAS}

AlEZA IZQuIERDO, Milagros (2001): «Sobre la presencia de voces de origen amerindio en la última edición del Diccionario de la Lengua Española», en HERnÁndez, César, Actas del VI Congreso Internacional, El español de América, Instituto Interuniversitario de Estudios de Iberoamérica y Portugal, Universidad de Valladolid (Tordesillas, octubre 2005).

Aleza IzQuierdo, Milagros y José María Enguita UtriLla (2002): El español de América: aproximación sincrónica, Valencia, Tirant lo Blanch.

AlezA IZQUIERDO, Milagros (2005): «Vacilaciones gráficas en el uso de los extranjerismos en la prensa de la Comunidad Valenciana», Quaderns de Filologia. Estudis Lingüístics 10, 12-29.

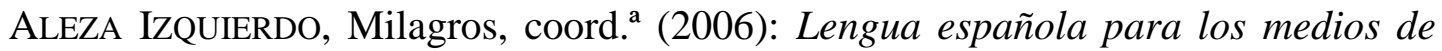
comunicación: usos y normas actuales, Valencia, Tirant lo Blanch.

AlezA IZQUIERDO, Milagros (2008): «Sobre la presencia de voces de origen extranjero en el $D P D »$ en Álvarez Tejedor, Antonio et alii (eds.), Lengua viva. Estudios ofrecidos a César Hernández Alonso, Valladolid, Universidad de Valladolid y Diputación de Valladolid, 255-270.

AleZA IZQUIERDO, Milagros coord. ${ }^{\mathrm{a}}$ (2010a): Normas y usos correctos en el español actual, Valencia, Tirant lo Blanch.

AlezA IZQUIERDO, Milagros, coord. ${ }^{a}$ (2010b): La lengua española en América: normas y usos actuales [en línea], Valencia, Universitat de València. http://www.uv.es/aleza/.

Alvar EZQuerra, Manuel (1999): Manual de redacción y estilo, Madrid, Istmo.

CANo Aguilar, Rafael (1999): El español a través de los tiempos, Madrid, Arco/Libros. Press.

Clyne, Michael (1972): Perspectives on Language Contact, Melbourne, Hawthorn

ESTORNELl PONS, María (2009): Neologismos en la prensa. Criterios para reconocer y caracterizar las unidades neológicas, Valencia, Universitat de València.

GIMÉNEZ FOLQUÉS, David (2010): «Introducción a los extranjerismos del Diccionario panhispánico de dudas y criterios de adaptación» en Aleza Izquierdo,

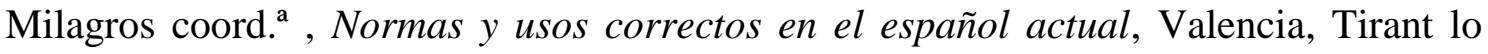
Blanch, págs. 217-228.

GIMÉNEZ FOLQUÉS, David (2011): Normativa académica, adaptación y uso de los extranjerismos en el español actual, Valencia, Universitat de València (Tesis doctoral). 
GómEz CAPUZ, Juan (1992): «La problemática de los extranjerismos en los libros de estilo: purismo y defensa de la lengua», en Laguna, A. y A. López García., eds. Doscents anys de promesa valenciana. I Congrés Internacional de Periodisme. Actes, Valencia, Generalitat Valenciana, 899-909.

GÓMEZ CAPUZ, Juan (1996): «Observaciones sobre la función de los extranjerismos en español coloquial: valores estilísticos, semánticos y pragmáticos», en Briz, Antonio; J. Ramón Gómez y M. J. Martínez, Pragmática y gramática del español hablado. Actas del II Simposio sobre análisis del discurso oral, Departamento de Filología Española/Libros Pórtico, Valencia/Zaragoza, 305-310.

Gómez CAPUZ, Juan (1997a): Anglicismos en español actual: su estudio en el registro coloquial, Facultat de Filologia de la Universitat de València. Servei de Publicacions de la Universitat de València.

Gómez CAPUZ, Juan (1997b): «Aspectos etimológicos y diacrónicos de los préstamos en la lexicografía española», leída en las Jornadas La lengua española: pasado y presente, celebradas en la Universidad de Valencia.

GóMEZ CAPUZ, Juan (1998): El préstamo lingüístico (conceptos, problemas y métodos), Anejo XXIX de la Revista «Cuadernos de Filología», Valencia, Universitat.

Gómez CAPuZ, Juan (2004): Préstamos del español: lengua y sociedad, en la colección «Cuadernos de Lengua Española», Madrid, Arco/Libros.

GómEz CAPUZ, Juan (2005): La inmigración léxica, Madrid, Arco/Libros, S.L.

Gómez TORREGO, Leonardo (1995): El léxico en el español actual: Uso y norma, Madrid, Arco.

GómEz TORREGO, Leonardo (2000): Ortografía del uso del español actual, Madrid, Ediciones SM, 2000.

Gómez ToRRegO, Leonardo (2007): Hablar y escribir correctamente, Gramática normativa del español actual (II), Madrid, Arco/Libros, S.L.

GómEZ TORREGO, Leonardo (2011): Ortografía y gramática. Las normas académicas: últimos cambios, Madrid, Ediciones SM.

HAENSCH, Günther (1975): «El préstamo lingüístico en el lenguaje coloquial y en las jergas» en Filología y Didáctica Hispánica. Festschrift Schneider, Hamburgo, 115-130.

LAPESA, Rafael (1942) (1981, 9a): Historia de la lengua española, Madrid, Gredos.

LÁZARO CARRETER, Fernando (1991): «El dardo en la palabra: extranjerismos solapados», $A B C, 14-7-91,3$

MEDINA LóPEZ, Javier (1997): Lenguas en contacto, Madrid, Arco/Libros, S.L.

Moliner, María (2007): Diccionario de uso del español, Madrid: Gredos.

PAYRATÓ, Lluis (1985): La interferencia lingüística (comentaris i exemples catalàcastellà), Curial Edicions Catalanes/Publicacions de l'Abadia de Montserrat. 
PRATT, Chris (1980): El anglicismo en el español peninsular contemporáneo, Madrid, Gredos.

Real ACAdEMia Española (1999): Ortografía de la lengua española, Madrid, Espasa.

Real Academia Española (2001): Diccionario de la Lengua Española, Madrid, Espasa.

Real academia Española y Asociación De Academias De la Lengua EsPaÑola (2005): Diccionario Panhispánico de Dudas, Madrid, Santillana.

Real ACAdemia Española y Asociación De ACAdemias De la Lengua ESPAÑOLA (2009): Nueva gramática de la lengua española, Madrid, Santillana. Volúmenes 1 (Morfología y Sintaxis) y 2 (Sintaxis).

REAL ACADEMIA ESPAÑOLA Y ASOCIACIÓN DE ACADEMIAS DE LA LENGUA ESPAÑOla (2010a): Nueva gramática de la lengua española, Madrid, Santillana. Volúmenes de Fonética y fonología.

REAL ACADEMIA ESPAÑOLA Y ASOCIACIÓN DE ACADEMIAS DE LA LENGUA ESPAÑOLA (2010b): Diccionario de americanismos, Madrid, Santillana.

REAL ACADEMIA ESPAÑOLA Y ASOCIACIÓN DE ACADEMIAS DE LA LENGUA ESPAÑOLA (2010c): Ortografía de la lengua española, Madrid, Espasa.

SECO, Manuel et alii (1999): Diccionario del español actual, Madrid, Santillana.

SECO, Manuel (2001): Diccionario de dudas y dificultades de la lengua española, Madrid, Espasa Calpe.

TORres Torres, Antonio (2000): «El español en los Estados Unidos de América» en El español de América, Barcelona, Edicions de la Universitat de Barcelona, 87-116. 